\title{
Effects of fusidic acid on staphylococcal keratitis
}

\author{
KHALID F TABBARA, SOBHI ANTONIOS, AND HENRY ALVAREZ \\ From the King Khaled Eye Specialist Hospital and Department of Ophthalmology, College of Medicine, King \\ Saud University, Riyadh, Saudi Arabia
}

SUMMARY We treated 20 consecutive patients suffering from staphylococcal keratitis with topical fusidic acid $1 \%$ suspension in a carbomer gel. Fifteen $(79 \%)$ of the isolated Staphylococcus epidermidis strains were resistant to methicillin, but all were sensitive to fusidic acid by in-vitro testing. The keratitis showed evidence of healing in $17(85 \%)$ of the 20 patients. The healing times ranged between 5 and 21 days (mean 10.5 days). In this open clinical trial fusidic acid proved to be a safe and effective antibiotic for the treatment of staphylococcal keratitis.

Bacterial infections of the cornea produce a wide spectrum of clinical signs and symptoms ranging from peripheral and superficial keratitis to central and deep corneal stromal ulcerations. Immediate initiation of specific antimicrobial therapy based on laboratory diagnosis is essential to eradicate the infectious agent and to prevent tissue damage and minimise scarring or melting. ${ }^{1-3}$ Preservation of vision and the integrity of the ocular tissues should be the ultimate goal of therapy in any infectious disease of the cornea.

Over the past two decades the use of topical steroids has increased with a corresponding increase in the risk of acquiring secondary infection by opportunistic bacteria. ${ }^{45}$ Moreover widespread use of antibiotics may have contributed to the increased incidence of $\beta$-lactamase and cephalosporinase producing Staphylococcus epidermidis ${ }^{6}$ in ocular infections. ${ }^{7-9}$ There is a paucity of commercially available topical antibiotics for staphylococcal ocular infections. ${ }^{10}$ Meanwhile, there has been an increase in strains of Staph Epidermidis resistant to a multiplicity of commercially available antibiotics inducing corneal infections. ${ }^{112}$ There is no highly effective topical antibiotic preparation against $\beta$-lactamaseproducing or methicillin-resistant staphylococci other than vancomycin. It is therefore conceded that search for effective antibacterial chemotherapeutic agents against these multiple antibiotic-resistant staphylococci and other Gram-positive cocci causing bacterial keratitis is essential in improving the visual outcome of patients suffering from bacterial keratitis.

Correspondence to K F Tabbara, MD, King Khaled Eye Specialist Hospital, PO Box 7191, Riyadh 11462, Kingdom of Saudi Arabia.
Topical fusidic acid (Fucithalmic) has recently become available as an ophthalmic preparation. Fucidin has been used since the early 1960 s for the treatment of severe systemic staphylococcal infections. ${ }^{13-15}$ Although vast experience has been gained in the systemic use of fucidin, there are only a limited number of clinical trials on the use of Fucithalmic viscodrops in the treatment of ocular infections. ${ }^{16}$ The main objective of this prospective open clinical trial was to assess the efficacy of $1 \%$ fusidic acid viscodrops in the treatment of bacterial keratitis caused by susceptible organisms.

\section{Patients and methods}

A total of 20 patients suffering from staphylococcal keratitis were included in this open clinical trial.

All the patients included in this study underwent an initial ophthalmological examination which included visual acuity testing, external eye examination, and biomicroscopic examination. Each patient's symptoms were recorded as well as past and current ocular treatment. Each patient had corneal scrapings which were subjected to Gram and Giemsa staining and plated on to blood agar, chocolate agar, and thioglycollate medium. ${ }^{2}$ Treatment was begun on the basis of Gram stain interpretation. Antibiotic sensitivity testing and complete species identification were performed on each isolate. Each patient's eye was examined by two ophthalmologists, each of whom examined the patient independently and then recorded the findings before and after initiating therapy. Slit-lamp photographs were taken before and during treatment. Each patient had a routine general health examination consisting of complete 
blood cell count, urine analysis, and blood chemistry tests (blood urea nitrogen, creatinine, and fasting blood sugar levels) both before and after treatment.

Each patient was started on a regimen of topical $1 \%$ fusidic acid and examined daily for one week. After that week the patient was examined every other day for an additional week, then weekly thereafter. Scrapings were repeated on some patients during the course of treatment.

\section{CRITERIA OF HEALING}

Healing of the keratitis was defined as improvement in visual acuity, decrease in size of corneal ulcer, decrease in degree of corneal infiltration and oedema, and increased visualisation of the iris details. The size of the corneal ulcer was measured and recorded, and the degree of corneal infiltration was graded as: $3+$ for severe infiltration with inability to see the iris details; $2+$ for moderate infiltration where the iris details are seen but hazy; and $1+$ where there was minimal infiltration with iris details clearly seen. ${ }^{1}$ The time of observed healing, that is, reepithelialisation of the corneal ulcer after treatment, was reported as the 'healing time' of the ulcer.

\section{INCLUSION CRITERIA}

Patients included in this study had a clinical diagnosis of active bacterial keratitis confirmed by positive smears and cultures. Patients who had clinical evidence of bacterial keratitis with Gram-positive cocci in their corneal scrapings were included in the study and started on topical fusidic acid. Corneal scrapings from all patients included in the study grew Staphylococcus spp. All the staphylococcal isolates recovered from these patients were susceptible to fusidic acid by in-vitro disc diffusion sensitivity tests. However, patients with evidence of corneal perforation were excluded from this study group.

\section{FUSIDIC ACID}

The antibiotic used topically consisted of fusidic acid viscodrops (Fucithalmic) in a suspension of fusidic acid hemihydrate, expressed as anhydrous fusidic acid; the active constituent contained $10 \mathrm{mg}$ per gram of the preparation $(1 \%)$. The preparation, a white aqueous gel, contained benzalkonium chloride and disodium edetate as preservatives, while sodium hydroxide was used for adjustment of the $\mathrm{pH}$ to $5 \cdot 5$.

The drug was instilled in the lower conjunctival sac by the nursing staff every two hours for a total of six applications per day.

\section{Results}

There were 18 male and two female patients, with an age range of 13 to 87 years, mean $56 \cdot 6$ years.
Table 1 Causative organisms and visual acuity before and after treatment with fusidic acid in patients with bacterial keratitis

\begin{tabular}{|c|c|c|c|c|c|}
\hline \multirow{2}{*}{$\begin{array}{l}\text { Case } \\
\text { no }\end{array}$} & \multirow{2}{*}{$\begin{array}{l}\text { Age, } \\
\text { sex }\end{array}$} & \multicolumn{2}{|l|}{ Vision } & \multirow{2}{*}{\multicolumn{2}{|c|}{$\begin{array}{l}\text { Healing Organism } \\
\text { time* }\end{array}$}} \\
\hline & & \multicolumn{2}{|c|}{$\begin{array}{l}\text { Pre- Post- } \\
\text { treatment treatment }\end{array}$} & & \\
\hline 1 & $76 \mathrm{M}$ & HM & $20 / 200$ & 5 & Staphylococcus epidermidis \\
\hline $2 \dagger$ & $38 \mathrm{M}$ & $20 / 200$ & $20 / 70$ & 14 & $\begin{array}{l}\text { Staphylococcus epidermidis } \\
\text { Streptococcus pneumoniae }\end{array}$ \\
\hline $3 \dagger$ & $72 \mathrm{~F}$ & HM & HM & 10 & $\begin{array}{l}\text { Staphylococcus epidermidis } \\
\text { Streptococcus pneumoniae }\end{array}$ \\
\hline 4 & $15 \mathrm{M}$ & $20 / 60$ & $20 / 50$ & 12 & Staphylococcus epidermidis \\
\hline 5 & $87 \mathrm{M}$ & HM & HM & 14 & Staphylococcus epidermidis \\
\hline 6 & $73 \mathrm{M}$ & HM & HM & 10 & Staphylococcus epidermidis \\
\hline 7 & $72 \mathrm{M}$ & $20 / 100$ & $20 / 100$ & 14 & Staphylococcus epidermidis \\
\hline 8 & $21 \mathrm{~F}$ & $\mathrm{CF} 2.5 \mathrm{~m}$ & $20 / 70$ & 14 & Staphylococcus epidermidis \\
\hline 9 & $50 \mathrm{M}$ & CF $1 \mathrm{~m}$ & CF $2 \mathrm{~m}$ & 8 & Staphylococcus aureus \\
\hline 10 & $13 \mathrm{M}$ & $20 / 60$ & $20 / 60$ & 7 & Staphylococcus epidermidis \\
\hline 11 & $85 \mathrm{M}$ & HM & HM & 5 & Staphylococcus epidermidis \\
\hline 12 & $71 \mathrm{M}$ & HM & HM & 10 & Staphylococcus epidermidis \\
\hline 13 & $74 \mathrm{M}$ & HM & $20 / 100$ & 10 & Staphylococcus epidermidis \\
\hline 14 & $37 \mathbf{M}$ & $20 / 200$ & $20 / 100$ & 21 & Staphylococcus epidermidis \\
\hline $15 \dagger$ & $72 \mathrm{~F}$ & HM & HM & 10 & $\begin{array}{l}\text { Staphylococcus epidermidis } \\
\text { Streptococcus pneumoniae }\end{array}$ \\
\hline 16 & $70 \mathrm{M}$ & LP & $20 / 200$ & 14 & Staphylococcus epidermidis \\
\hline 17 & $25 \mathrm{M}$ & $20 / 100$ & $20 / 50$ & 6 & Staphylococcus epidermidis \\
\hline 18 & $61 \mathrm{M}$ & HM & $20 / 160$ & 10 & Staphylococcus epidermidis \\
\hline 19 & $70 \mathrm{M}$ & $\mathrm{CF} 60 \mathrm{~cm}$ & $\mathrm{CCF} 1.5 \mathrm{~m}$ & 12 & Staphylococcus epidermidis \\
\hline 20 & $51 \mathrm{M}$ & CF $30 \mathrm{~cm}$ & $1 \mathrm{CF} 2.5 \mathrm{~m}$ & 5 & Staphylococcus epidermidis \\
\hline
\end{tabular}

$\mathbf{L P}=$ light perception.

HM= hand movement.

$\mathrm{CF}=$ counting fingers.

*Days for complete re-epithelialisation after initiation of therapy.

†Patients who did not respond to topical fusidic acid alone and other antibiotics had to be administered.

Table 1 shows the visual acuity before and four weeks after treatment with fusidic acid $1 \%$ viscodrops. Seventeen $(85 \%)$ patients improved clinically after topical therapy. Eleven (55\%) of the 20 patients had improvement in visual acuity after treatment. In six patients $(30 \%)$, although the ulcer healed, visual acuity did not improve. This was attributed to corneal scarring or other associated ocular disorders such as irregular astigmatism, cataract, or glaucoma. Three patients either did not respond or worsened on topical therapy with fusidic acid. Subconjunctival injections of other antibiotics such as gentamicin or cephazolin were then added to their therapeutic regimen. Repeat corneal scrapings and cultures showed no evidence of bacterial growth.

\section{HEALING OF KERATITIS}

Keratitis showed evidence of healing in $17(85 \%)$ of the 20 patients. Four patients with corneal ulcers had been unsuccessfully treated at the time of initial examination with other antibiotics, including gentamicin and chloramphenicol. These antibiotics were discontinued when the patients were entered 
into the study. The corneal ulcers showed complete re-epithelialisation within five days in three $(15 \%)$ patients, six to 10 days in nine $(45 \%)$ patients, 11 to 15 days in seven $(35 \%)$ patients, and 21 days in one patient $(5 \%)$. The average healing time for the corneal ulcers caused by staphylococci ranged from five to 21 days, with a mean healing time of 11.5 days.

\section{CAUSATIVE ORGANISMS}

The causative organism among 16 patients was Staphylococcus epidermidis. There were three cases of mixed infection with Streptococcus pneumoniae and Staphylococcus epidermidis. In one patient the organism was Staphylococcus aureus (Table 1). Invitro sensitivity tests revealed that out of 19 isolates of Staphylococcus epidermidis 15 (79\%) were resistant to methicillin, $12(60 \%)$ to bacitracin, and $16(80 \%)$ to erythromycin. All 19 strains of Staphylococcus epidermidis and one strain of Staphylococcus aureus were sensitive to fusidic acid. In the three patients who had mixed infection other antibiotics were added to the therapeutic regimen, such as penicillin $\mathrm{G}$ or cephazolin.

\section{Discussion}

The aetiology of bacterial keratitis varies from one place to another. In Saudi Arabia Staphylococcus species (epidermidis and aureus) are the most frequently encountered causative organisms of bacterial corneal ulcers. ${ }^{911}$

We found that topical use of fusidic acid appears to be effective in ameliorating corneal ulcers caused by antibiotic-resistant strains of staphylococci, in particular methicillin-resistant and $\beta$-lactamase producing staphylococci. Fusidic acid is of unique value as there are no highly effective, commercially available, topical antibiotic preparations against many of these staphylococci.

The remarkable clinical improvement of bacterial corneal ulcers caused by staphylococci following therapy with topical fusidic acid is consistent with the excellent ocular tissue penetration of fusidic acid which has been demonstrated by our group. High concentrations of fusidic acid were found in the corneal stroma and aqueous humour following topical use in the rabbit. Corneal tissue levels in the rabbit one hour after topical application of $1 \%$ fusidic acid were $10.6 \mathrm{mg} / 100 \mathrm{mg}$ in intact corneal epithelium and $13.8 \mathrm{mg} / 100 \mathrm{mg}$ in corneas with denuded epithelium. ${ }^{17}$ Fusidic acid is bactericidal at concentrations close to that of the minimum inhibitory concentrations (MIC) of 0.03 to $0.16 \mathrm{~g} / 1 .{ }^{17}{ }^{18}$ The ability of fusidic acid to penetrate ocular tissues with intact corneal epithelium makes this antibiotic useful in the treatment of deep staphylococcal keratitis.
The incidence of multiple antibiotic-resistant strains of staphylococci is increasing, especially among patients in hospital. Recent reports have cited the effectiveness of topical vancomycin in resistant cases of blephatoconjunctivitis. ${ }^{1920}$ Sensitivity testing to bacitracin, a commercially available ophthalmic preparation, was not reported in the cases presented by these authors. Although vancomycin is an excellent antistaphylococcal antibiotic, we consider it should be held in reserve for strains of staphylococci resistant to other commercially available preparations. Furthermore, commercially prepared antibiotics are usually well tolerated by patients, readily available, stable, cost effective, and less likely to become contaminated from improper preparation of storage.

It is conceded that this is an open clinical trial and not a double-blind placebo-controlled clinical study. For self-evident reasons, double-blind placebocontrolled clinical trials cannot be carried out in man. Bacterial corneal ulcers must be managed early and specific antibiotics initiated promptly to prevent irreversible damage to the corneal tissue. In conclusion, the topical use of $1 \%$ fusidic acid proved safe and effective in the treatment of staphylococcal keratitis in this open clinical trial.

\section{References}

1 Hyndiuk RA, Skorich DN, Burd EM. Bacterial keratitis. In: Tabbara KF, Hyndiuk RA, eds. Infections of the eye. Boston: Little, Brown, 1986: 303-30.

2 Hyndiuk RA, Seidelman S. Clinical and laboratory techniques in external ocular disease and endophthalmitis. In: Fedukowicz $\mathrm{HB}$, ed. External infections of the eye. New York: AppletonCentury Crofts, 1978; 2: 258-75.

3 Jones DB. Strategy for the initial management of suspected microbial keratitis. In: Boswell HF, ed. Symposium on medical and surgical diseases of the cornea. St Louis: Mosby, 1980: 86119.

4 Hyndiuk RA, Chin GN. Corticosteroid therapy in corneal disease. Int Ophthalmol Clin 1973; 13: 103.

5 Kleinert RW. Corticosteroid use in ocular infectious disease. In: Tabbara KF, Hyndiuk RA, eds. Infections of the eye. Boston: Little, Brown, 1986: 293-302.

6 Jones RN. Selection of antimicrobial agents for susceptibility testing. College of American Pathologists. Summing Up 1985; 15 (2): 3 .

7 Forster RK, Zachary IG, Cottingham AJ Jr, Norton EWD. Further observations on the diagnosis, cause, and treatment of endophthalmitis. Am J Ophthalmol 1976; 81: 52-6.

8 Kucers A, Bennett JM. The use of antibiotics. 3rd ed. Exeter: Heinemann, 1979: 97.

9 Tabbara KF, Lawson NA, Burd EM. In vitro susceptibility to fusidic acid of clinically significant staphylococcal isolates from ocular infections. Saudi Med J 1987; 8: 167-70.

10 Storich DN, Hyndiuk RA, Davis SD. Efficacy of fortified antibiotic ointments in the treatment of bacterial keratitis. Ocular Microbiology and Immunology Group Meeting, American Academy of Ophthalmology, 28 September 1985.

11 Byrne-Rhodes KA, Anicete GR. Common isolates and in vitro antibiotic susceptibility in microbial keratitis in Saudi Arabia. Saudi Bull Ophthalmol 1988; 3: 17-24. 
12 Richardson JF, Marples RR. Changing resistance to antimicrobial drugs and resistance typing in clinically significant strains of Staphylococcus epidermidis. J Med Microbiol 1982; 15: 475-84.

13 Cusak FB. Fucidin in staphylococcal septicaemia. Lancet 1962; ii: 403.

14 Copperman IJ. The prolonged use of intravenous fusidic acid in severe staphylococcal infection. Br J Clin Pract 1972; 26: 83-4.

15 Crosbie RB. Treatment of staphylococcal infection with 'fucidin'. Br Med J 1963; i: 788-94.

16 Taylor PB, Tabbara KF, Burd EM. The effect of preoperative fusidic acid on the normal eyelid and conjunctival bacterial flora. Br J Ophthalmol 1988; 72: 206-9.
17 Taylor PB, Burd E, Tabbara KF. Corneal and intraocular penetration of topical and subconjunctival fusidic acid. $\mathrm{Br} J$ Ophthalmol 1987; 71: 598-601.

18 Steward, GT. Steroid antibiotics. Pharmakotherapie 1964; 2: $137-48$.

19 Khan JA, Hoover D, Ide CH. Methicillin-resistant Staphylococcus epidermidis blepharitis. Am J Ophthalmol 1984; 98: 562-5.

20 Fleisher AB, Hoover DL, Khan JA, et al. Staphylococcus epidermidis blepharoconjunctivitis. Am J Ophthalmol 1986; 101: 283-7.

Accepted for publication 19 January 1988. 